\title{
Assessment of mitral annuloplasty ring by cardiac computed tomography: Correlation with echocardiographic parameters and comparison between two different ring types
}

\author{
Young Joo Suh, MD, ${ }^{a}$ Byung-Chul Chang, MD, PhD, ${ }^{b}$ Dong Jin Im, MD, ${ }^{a}$ Yun Jung Kim, MD, ${ }^{a}$ \\ Yoo Jin Hong, $\mathrm{MD},{ }^{\mathrm{a}}$ Geu-Ru Hong, $\mathrm{MD}, \mathrm{PhD},{ }^{\mathrm{c}}$ and Young Jin Kim, MD, $\mathrm{PhD}^{\mathrm{a}}$
}

\begin{abstract}
Objectives: This study investigated computed tomographic (CT) appearance after mitral ring annuloplasty, especially comparing CT findings between patients with normal pressure gradient (PG) and patients with functional mitral stenosis (MS) and between 2 commonly used types of annuloplasty ring.

Methods: A total of 45 cardiac CT scans in patients who underwent mitral ring annuloplasty (Carpentier-Edwards ring, $\mathrm{n}=27$; Duran ring, $\mathrm{n}=18$ ) were retrospectively reviewed. On CT scan, presence of significant pannus around the annuloplasty ring, presence of leaflet thickening, and maximal mitral opening area were analyzed. CT findings were compared between patients with normal PG and patients with functional MS (mean diastolic PG $\geq 5 \mathrm{~mm} \mathrm{Hg}$ ). Incidences of functional MS and CT findings were compared between ring types.
\end{abstract}

Results: Significant pannus was present in 10 cases and leaflet thickening in 31 cases, and maximal opening area was $2.34 \pm 0.717 \mathrm{~cm}^{2}$. Valve opening area on CT was positively correlated with mitral valve area on transthoracic echocardiography and negatively correlated with mean diastolic PG. Mean diastolic PG was significantly elevated with increasing pannus severity. Patients with functional MS had more significant pannus than patients with normal PG. The Duran ring group had higher mean diastolic PG, smaller mitral valve area, and higher incidence of functional MS than the Carpentier-Edwards ring group $(P<.05)$. The proportion of pannus and significant pannus was significantly higher in the Duran ring group $(P<.05)$.

Conclusions: Significant pannus around the annuloplasty ring on CT may cause functional MS after mitral ring annuloplasty. This may occur more frequently with the Duran ring. (J Thorac Cardiovasc Surg 2015;150:1082-90)

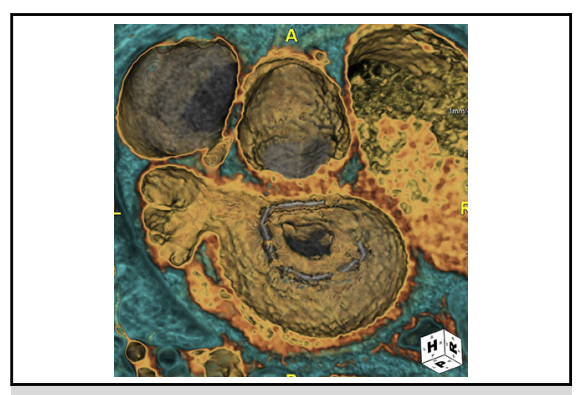

Computed tomographic image shows severe pannus causing mitral stenosis in a Duran annuloplasty ring.

\section{Central Message}

Pannus around the annuloplasty ring seen on computed tomography may cause functional mitral stenosis after mitral ring annuloplasty and may occur more frequently with the Duran ring.

\section{Perspective}

Mitral stenosis after mitral valve annuloplasty is mostly caused by pannus from the annuloplasty ring and is related to annuloplasty ring type. On computed tomography after mitral valve annuloplasty, patients with functional mitral stenosis had more significant pannus formation, and the Duran ring had a higher incidence of pannus formation and a smaller opening area than the Carpentier-Edwards ring. Cardiac computed tomography can help to evaluate pressure gradient elevation in patients with the Duran ring.

See Editorial Commentary page 1091.
Mitral valve (MV) repair is widely regarded as the procedure of choice for significant nonrheumatic mitral regurgitation requiring surgery. Recurrent mitral regurgitation is the most common cause of failure of MV repair, but mitral

From the a Department of Radiology, Research Institute of Radiological Science, Severance Hospital, Yonsei University College of Medicine, Seoul, Korea; the ${ }^{\mathrm{b}}$ Department of Cardiovascular Surgery, Severance Cardiovascular Hospital, Yonsei University College of Medicine, Seoul, Korea; and the ${ }^{\mathrm{c}}$ Division of Cardiology, Severance Cardiovascular Hospital, Yonsei University College of Medicine, Seoul, Korea.

Received for publication Jan 24, 2015; revisions received June 25, 2015; accepted for publication July 3, 2015; available ahead of print Aug 12, 2015. stenosis (MS) is relatively rare after MV repair performed to correct mitral regurgitation caused by myxomatous disease or ischemic MV disease. ${ }^{1-5}$ MS after ring annuloplasty has been reported to be mostly caused by pannus overgrowth

\footnotetext{
Address for reprints: Young Jin Kim, MD, PhD, Department of Radiology, Yonsei University College of Medicine, 50-1 Yonsei-ro, Seodaemun-gu, Seoul 120-752,

Korea (E-mail: dryj@yuhs.ac). $0022-5223 / \$ 36.00$

Copyright (c) 2015 by The American Association for Thoracic Surgery http://dx.doi.org/10.1016/j.jtcvs.2015.07.019
} 


$$
\begin{aligned}
& \text { Abbreviations and Acronyms } \\
& \begin{aligned}
\text { MV } & =\text { mitral valve } \\
\text { MS } & =\text { mitral stenosis } \\
\text { CT } & =\text { computed tomography } \\
\text { PG } & =\text { pressure gradient } \\
\text { TTE } & =\text { transthoracic echocardiography } \\
\text { CE } & =\text { Carpentier-Edwards } \\
\text { MVA } & =\text { mitral valve area }
\end{aligned}
\end{aligned}
$$

from the annuloplasty ring, and the type of annuloplasty ring used has been believed to be related to pannus development. ${ }^{6-10}$ Pannus formation is considered to be a foreign-body reaction to the synthetic annuloplasty ring and has been observed frequently after insertion of the flexible Duran annuloplasty ring (Medtronic, Inc, Minneapolis, Minn). ${ }^{6-10}$

Recently, cardiac computed tomography (CT) has emerged as a novel technique to evaluate cardiac valves, including prosthetic valves. Little is known, however, regarding CT appearance after MV repair. We hypothesized that $\mathrm{CT}$ findings after MV ring annuloplasty might differ according to echocardiographic parameters and different types of annuloplasty rings.

The purpose of our study was to investigate CT appearance after mitral ring annuloplasty, especially to compare $\mathrm{CT}$ findings between patients with normal pressure gradient (PG) and patients with functional MS on transthoracic echocardiography (TTE), and between two commonly used types of annuloplasty ring (flexible Duran ring and rigid Carpentier-Edwards [CE] ring [Edwards Lifesciences Corporation, Irvine, Calif]).

\section{MATERIALS AND METHODS \\ Patients}

The institutional review board of our institution approved this retrospective study, and informed consent was waived. From surgical records from January 1995 to December 2013, we retrieved data on 846 patients who underwent MV repair in our institution. Of them, 356 had been included in the study population of a prospective, randomized trial conducted in our institution from January 1995 to August $2005 .^{11}$ Among these patients, we included 68 patients who had undergone mitral annuloplasty and who had undergone cardiac CT from March 2008 to August 2014. Patients with an interval of less than 1 year between mitral annuloplasty and CT $(\mathrm{n}=13)$, patients with rheumatic valve disease as original etiology $(n=6)$, patients with no ring or with other ring types than the CE ring or Duran ring $(n=3)$, and patients with nonassessable image quality of CT scans as result of severe artifacts $(n=2)$ were excluded from the study (Figure 1). A total of 45 patients were included in the final analysis; patients received either a CE Classic ring or a Duran ring during their operation. Demographic data and information on the annuloplasty ring were collected from electronic medical records. Patients underwent cardiac CT for suspected coronary artery disease $(n=18)$, evaluation of coronary bypass graft $(n=18)$, suspected MV dysfunction on TTE $(\mathrm{n}=5)$, and pulmonary vein evaluation before radiofrequency ablation $(\mathrm{n}=4)$.

\section{CT Acquisition}

All CT scans were performed with a dual-source CT scanner (SOMATOM Definition Flash; Siemens Healthcare, Forchheim, Germany) or a 64-slice multidetector CT (Somatom Sensation 64; Siemens Medical Solution, Erlangen, Germany). In the absence of contraindications, patients with a heart rate greater than 65 beats/min received $50 \mathrm{mg}$ of an oral $\beta$ blocker (metoprolol tartrate) 1 hour before examination and a $0.3-\mathrm{mg}$ sublingual dose of nitroglycerin were administered just before the scan. Scans were performed with retrospectively electrocardiographically gated data acquisition or prospectively electrocardiographically gated acquisition mode according to the CT indication. For each patient, the appropriate interval between injection of the contrast agent and initiation of scanning was determined by the timing bolus technique. After a bolus injection of $10 \mathrm{~mL}$ of iopamidol (Pamiray, $370 \mathrm{mg}$ of iodine/mL; Dongkook Pharma, Seoul, Korea) followed by $20 \mathrm{~mL}$ of saline solution at $5 \mathrm{~mL} / \mathrm{s}$, optimal delay times were determined by automatic evaluation of the contrast enhancement in the ascending aorta. All CT scans were performed with the triple-phase injection method $(70 \mathrm{~mL}$ of iopamidol followed by $30 \mathrm{~mL}$ of $30 \%$ blended iopamidol with saline solution and $20 \mathrm{~mL}$ of saline solution at $5 \mathrm{~mL} / \mathrm{s}$ ).

Image reconstruction was performed with a medium kernel (b36f), and the reconstruction slice thickness was $0.75 \mathrm{~mm}$ with $0.5-\mathrm{mm}$ increments. For all patients, 10 transverse data sets were reconstructed for every $10 \%$ of the cardiac cycle $(0 \%$ to $90 \%)$. Reconstructed images were transferred to an image server and analyzed with dedicated 3-dimensional software (Aquarius iNtuition, version 4.4.11; TeraRecon, Inc, San Mateo, Calif).

\section{Image Analysis}

All CT analyses were performed by a single radiologist (Y.J.S.), who was blinded to clinical information and TTE results. Valve evaluation was performed with multiplanar reformatted images in a short-axis image of the MV annulus, a long-axis view of the left ventricle, and a 4-chamber view. Assessment of MV and annuloplasty ring consisted of evaluation of pannus formation, valve leaflet thickening, valve opening area, diastolic opening angle, and systolic coaptation angles of anterior and posterior mitral leaflets, tenting height and mitral annular size. The short-axis view of the mitral annulus was used to evaluate the presence of pannus around the annuloplasty ring. If a low-attenuating pannus was present, the severity of pannus was evaluated by both qualitative and quantitative methods. For qualitative assessment, pannus severity was visually graded according to the proportion of the diameter of the narrowest area by the pannus to the area inside the annuloplasty ring and classified as insignificant or significant. Pannus was considered to be significant if the narrowing as a result of the pannus was more than $50 \%$ of the diameter. For quantitative assessment, the area inside the annuloplasty ring and inside the pannus at the mitral annular level was measured, and the proportion of the area inside the pannus to the area inside the annuloplasty ring was calculated (Figure 2). For evaluation of valve leaflet thickening, the maximal thickness of the MV leaflet was measured, and the leaflet was considered to be thickened when leaflet thickness was greater than $2 \mathrm{~mm} .{ }^{12}$ In cases in which multiphase data were available, the opening area of the MV was measured at the maximal opening point of the valve tip. ${ }^{13}$ The diastolic opening angle and systolic coaptation angles of the anterior and posterior mitral leaflets and the tenting height on systole were quantified in a 4-chamber view. ${ }^{14,15}$ For assessment of mitral ring size, the maximal and minimal diameters inside the annuloplasty ring were measured at the diastolic phase (maximal opening point of the MV). The annular area was defined as the area within the annuloplasty ring on a short-axis view. The annular sphericity index was calculated by dividing the maximal annular diameter by minimal diameter, which was modified from echocardiographic measurements. ${ }^{16}$

\section{Data Analysis}

Clinical data were collected from medical records for etiology of original valve disease, type and size of annuloplasty ring, concurrent other 


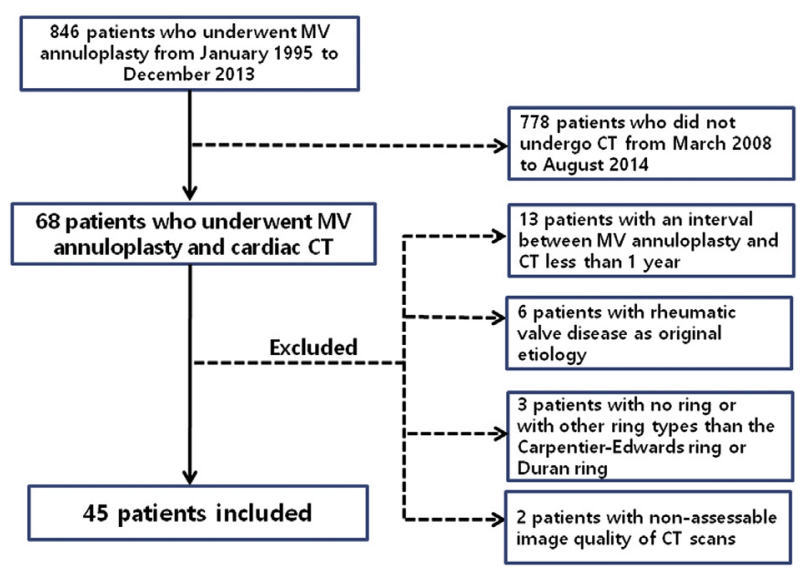

FIGURE 1. A flow diagram of the study population. $M V$, Mitral valve; $C T$, computed tomography.

valve operation or coronary artery bypass graft surgery, and follow-up data for reoperation. TTE data were recorded for mean diastolic PG, MV area (MVA, by pressure half time), presence of mitral regurgitation, and left ventricular ejection fraction.

\section{Statistical Analysis}

Statistical analyses were performed with computerized statistic programs (MedCalc for Windows, version 11.5.0.0; MedCalc Software, Mariakerke, Belgium; and SAS version 9.2; SAS Institute Inc, Cary, NC). Normally distributed data were identified with the Shapiro-Wilk W test. Continuous variables were presented as mean \pm SD or median with interquartile range (25th-75th percentile) and compared with the independent $t$ test for normally distributed data or the Mann-Whitney $U$ test for nonnormally distributed data. The correlations between CT findings (leaflet thickness and maximal opening area) and TTE parameters (PG and MVA) were analyzed with the Pearson correlation coefficient. Correlation analysis between PG on TTE with multiple echocardiographic data and maximal opening area on CT was performed with a linear mixed model by the Hamlett method for accounting repeated measurements. ${ }^{17}$ Comparison of CT findings between patients with normal PG and patients with elevated PG and comparison of incidence of functional MS on TTE, presence of pannus, and leaflet thickening on CT between the 2 ring types (Duran ring vs CE ring) was performed with $\chi^{2}$ statistics or the Fisher exact test. Comparison of CT findings between groups were adjusted for the interval between MV repair and CT by means of the linear regression analysis for continuous variables or the logistic regression analysis with maximum likelihood estimation or the Firth penalized maximum likelihood estimation for categoric variables as appropriate. Difference in changes of PGs with interval between 2 ring types was analyzed using linear-mixed model; considering ring type, interval, and interaction term between ring type and interval as fixed effect, and individual patient as random intercept, and interval as random slope.

\section{RESULTS Patients}

The final study population consisted of 45 patients, 27 patients with the CE ring and 18 patients with the Duran ring. Clinical, TTE, and CT information is summarized in Table 1.

\section{CT Analysis of Annuloplasty Rings}

Pannus around the annuloplasty ring was observed in 29 of 45 cases $(64.4 \%)$. Visual grading of the pannus severity showed that significant pannus was present in 10 patients. Measurement of the ratio of the area inside the pannus to that inside the annuloplasty ring was significantly different between patients with insignificant pannus and patients with significant pannus (Figure 2; $P<.05$ ). Leaflet thickness was measured as $2.18 \pm 0.86 \mathrm{~mm}$, and leaflet thickening (>2 mm) was present in 31 of 45 patients $(68.9 \%)$. In 23 of 45 patients, measuring the valve opening area was not feasible because multiphase $\mathrm{CT}$ images were unavailable $(n=21)$ or significant paravalvular regurgitation as a result of detachment of the annuloplasty ring was present $(n=2)$. Valve opening area was measured at $2.34 \pm 0.717 \mathrm{~cm}^{2}$.
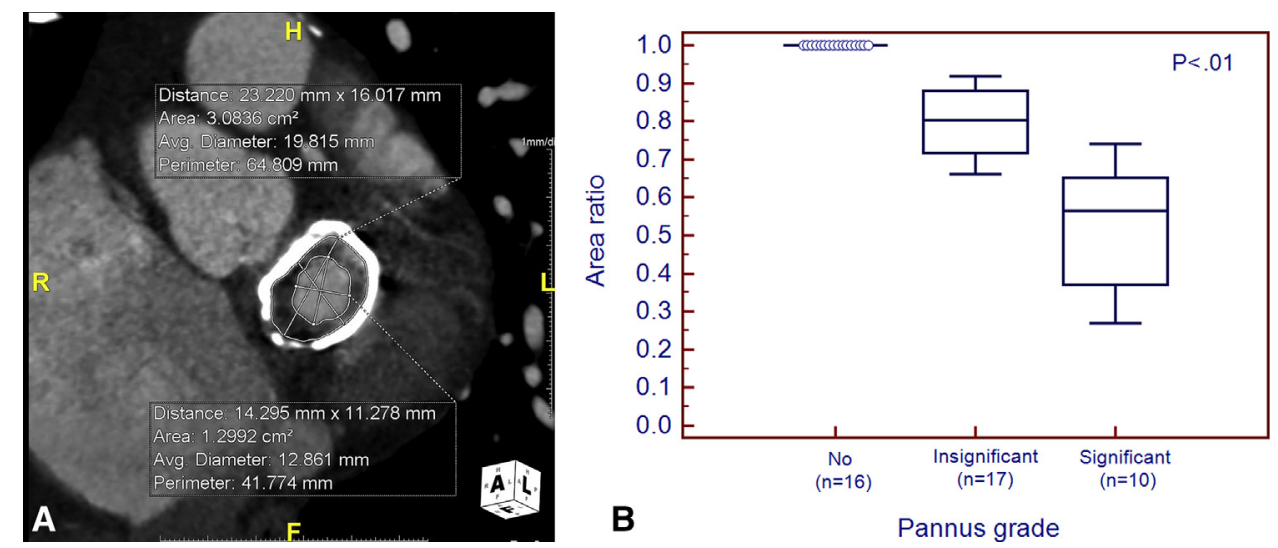

FIGURE 2. Correlation of visual grading and quantitative measurement in pannus severity. A, Short-axis computed tomographic image of the mitral valve in a 67-year-old male patient with a $29-\mathrm{mm}$ Duran annuloplasty ring shows the significant pannus. The maximal and minimal annular diameter and area inside the annuloplasty ring measured on computed tomography were $23.2 \mathrm{~mm}, 16.0 \mathrm{~mm}$, and $3.08 \mathrm{~cm}^{2}$, respectively. The ratio of the area inside the pannus to the inside of the annuloplasty ring was 0.42 . B, The box-and-whisker plot shows the difference in area ratio according to pannus severity. The box represents the values from the lower to upper quartile (25th-75th percentile), and the middle line represents the median. A line extends from the minimum to the maximum value. Area ratio refers to the ratio of area inside the pannus to the inside of the annuloplasty. 
TABLE 1. Clinical characteristics

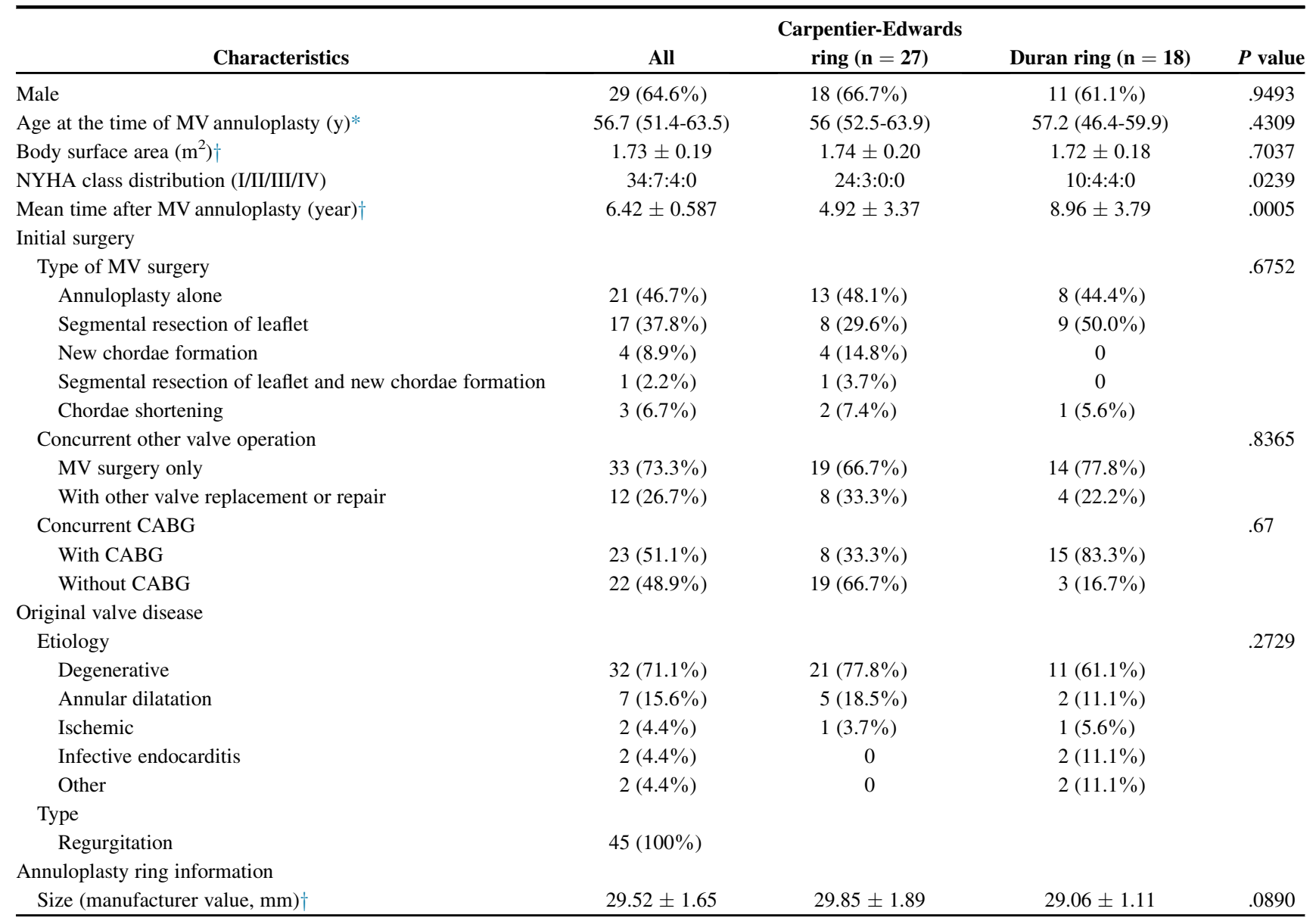

Unless otherwise indicated, data are numbers of patients, with percentages in parentheses. $M V$, Mitral valve; $N Y H A$, New York Heart Association; $C A B G$, coronary artery bypass graft surgery. *Represents parameters which reject normality and data are median and interquartile range (25th-75th percentile). $\dagger$ Data are mean \pm SD.

In patients with significant pannus, the valve opening area on CT was smaller than in patients with no or insignificant pannus $\left(1.71 \mathrm{~cm}^{2}\right.$ vs $2.63 \mathrm{~cm}^{2} ; P<.05$; Figure 3$)$. No significant difference in leaflet thickness was observed between patients with significant pannus and those with no or insignificant pannus $(2.43 \pm 1.11 \mathrm{~mm}$ vs $2.12 \pm 0.794 \mathrm{~mm}$; $P=.352)$.

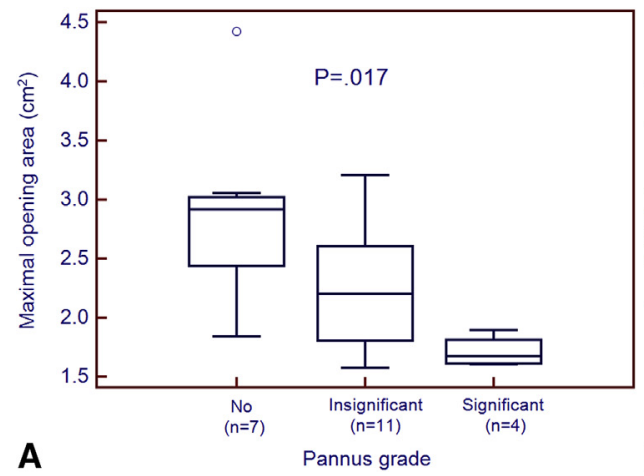

FIGURE 3. Box-and-whisker plots of the maximal opening area (A) and the leaflet thickness (B) on computed tomography according to pannus severity. The box represents the values from the lower to upper quartile (25th-75th percentile), and the middle line represents the median. A line extends from the minimum to the maximum value. 

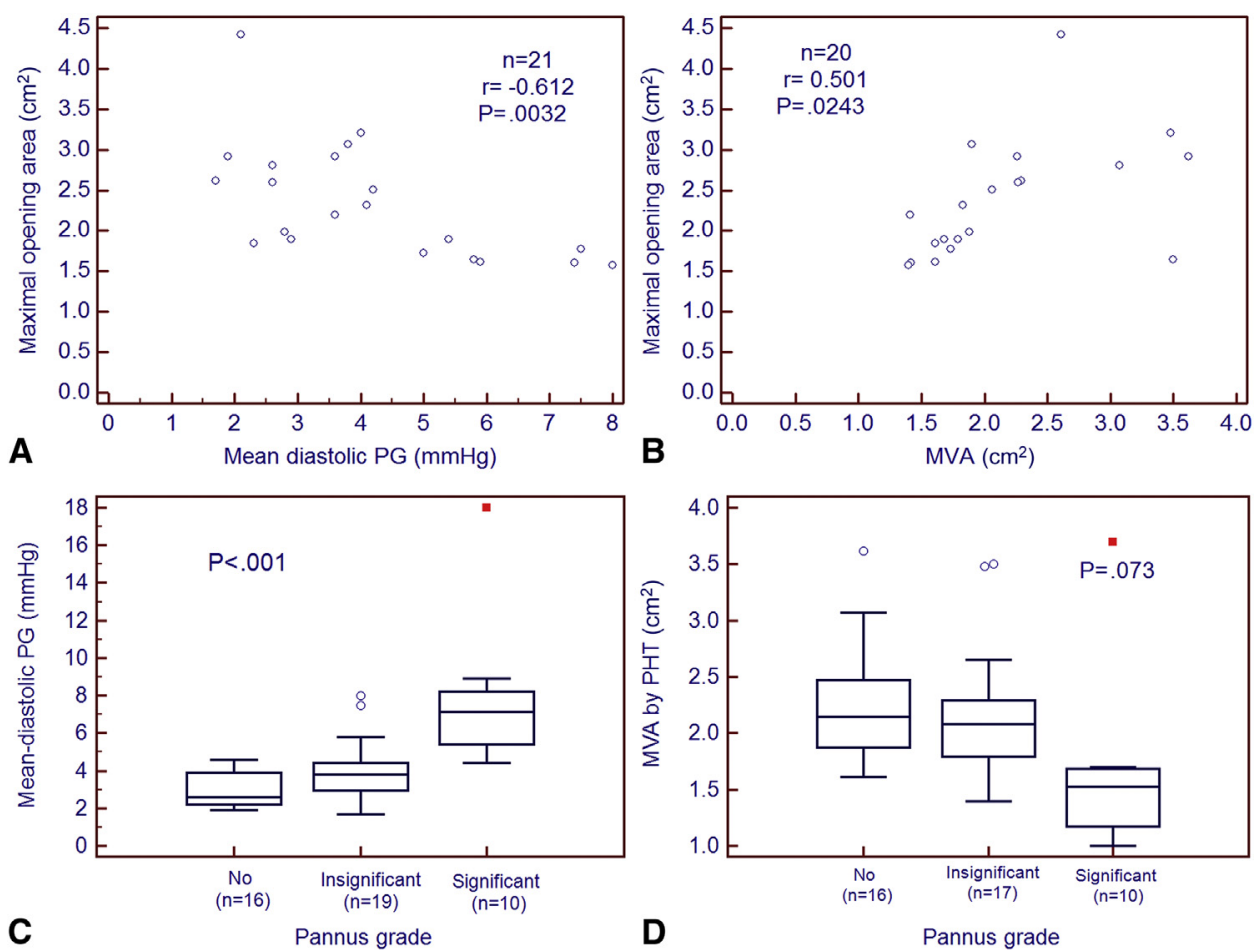

FIGURE 4. Correlation between computed tomographic measurements and transthoracic echocardiographic parameters. A and B, Scatter diagrams showing a negative correlation between the mean pressure gradient $(P G)$ on transthoracic echocardiography and the maximal opening area on computed tomography (A), and a positive correlation between mitral valve area (MVA) on transthoracic echocardiography and the maximal opening area measured on computed tomography (B). C and D, Box-and-whisker plots show differences in (C) the mean pressure gradient and (D) mitral valve area according to pannus severity. The box represents the values from the lower to upper quartile (25th-75th percentile), and the middle line represents the median. A line extends from the minimum to the maximum value. $P H T$, Pressure half time.

PG $(P=.0036)$ and 0.551 between maximal opening area and MVA on TTE $(P=.014)$. The correlation coefficient of PG with multiple echocardiographic data was estimated as 0.5541 , and the correlation coefficient between PG and maximal opening area on CT was -0.4887 . With increasing pannus severity, the mean diastolic PG was significantly elevated. Thirteen patients ( 4 with CE rings and 9 with
Duran rings) met the criteria for functional MS by having a mean diastolic PG of at least $5 \mathrm{~mm} \mathrm{Hg}$. In patients with elevated PG, CT showed a higher incidence of pannus and significant pannus than in patients with normal range PG, even after adjustment of the interval between MV repair and CT scan, but leaflet thickening and maximal opening area on CT were not different (Table 2).

TABLE 2. Clinical and computed tomographic findings according to transthoracic echocardiographic parameters

\begin{tabular}{|c|c|c|c|c|}
\hline Variables & Elevated PG $(\mathbf{n}=13)$ & Normal PG $(\mathbf{n}=32)$ & $P$ value & Adjusted $P$ value \\
\hline \multicolumn{5}{|l|}{ Clinical findings } \\
\hline Inserted ring size (manufacturer value, $\mathrm{mm}$ )* & $29.07 \pm 1.19$ & $29.71 \pm 1.79$ & .2502 & N/A \\
\hline Duran ring & $9(69.23 \%)$ & $9(28.13 \%)$ & .0267 & N/A \\
\hline Mean diastolic transmitral pressure gradient $(\mathrm{mm} \mathrm{Hg})^{*}$ & $7.65 \pm 3.36$ & $3.22 \pm 0.88$ & .0005 & N/A \\
\hline \multicolumn{5}{|l|}{ CT findings } \\
\hline Pannus & $13(100 \%)$ & $16(50 \%)$ & .0014 & .0353 \\
\hline Significant pannus & $9(69.23 \%)$ & $1(3.13 \%)$ & $<.0001$ & .0015 \\
\hline Leaflet thickness on CT $(\mathrm{mm})^{*}$ & $2.49 \pm 1.05$ & $2.05 \pm 0.75(\mathrm{n}=31)$ & .1876 & .2056 \\
\hline Leaflet thickening on CT $(>2 \mathrm{~mm})$ & $12(92.31 \%)$ & $19(59.38 \%)$ & .0378 & .0611 \\
\hline Maximal annular diameter measured on $\mathrm{CT}(\mathrm{mm})^{*}$ & $26.32 \pm 2.12$ & $28.05 \pm 2.39(\mathrm{n}=30)$ & .0295 & .0420 \\
\hline Minimal annular diameter measured on CT $(\mathrm{mm})^{*}$ & $17.28 \pm 1.72$ & $17.74 \pm 1.80(\mathrm{n}=30)$ & .4396 & .2105 \\
\hline Sphericity index of mitral annulus* & $1.54 \pm 0.20$ & $1.59 \pm 0.17(\mathrm{n}=30)$ & .3552 & .6022 \\
\hline Annular area measured on CT $\left(\mathrm{cm}^{2}\right)^{*}$ & $3.69 \pm 0.42$ & $3.96 \pm 0.57(\mathrm{n}=30)$ & .1191 & .0762 \\
\hline
\end{tabular}

Unless otherwise indicated, data are numbers of patients, with percentages in parentheses. $P G$, Pressure gradient; $N / A$, not applicable; $C T$, computed tomography. ${ }^{*}$ Data are mean $\pm \mathrm{SD}$. 
TABLE 3. Clinical, transthoracic echocardiographic, and computed tomographic findings according to ring type

\begin{tabular}{|c|c|c|c|c|}
\hline Variables & Carpentier-Edwards ring $(n=27)$ & Duran ring $(\mathrm{n}=18)$ & $P$ value & Adjusted $P$ value \\
\hline \multicolumn{5}{|c|}{ Echocardiographic findings at immediate postoperative period } \\
\hline Mean diastolic PG & $4.04 \pm 1.56(\mathrm{n}=23)$ & $4.34 \pm 1.45(\mathrm{n}=12)$ & .5830 & \\
\hline MVA (by pressure half time) $\dagger$ & $2.40 \pm 0.51(\mathrm{n}=22)$ & $2.44 \pm 0.48(\mathrm{n}=11)$ & .8462 & \\
\hline \multicolumn{5}{|l|}{ Echocardiographic findings at the time of CT } \\
\hline Mean diastolic $\mathrm{PG} \dagger$ & $3.52(2.49-4.20)$ & $4.75(3.80-7.20)$ & .0009 & \\
\hline MVA (by pressure half time) $\dagger$ & $2.08(1.83-2.33)$ & $1.69(1.48-2.13)$ & .0337 & \\
\hline Functional MS $(\geq 5 \mathrm{~mm} \mathrm{Hg})^{*}$ & $4(14.81 \%)$ & $9(50 \%)$ & .0267 & \\
\hline Left ventricular ejection fraction $(\%) \dagger$ & $61(55.5-64.8)$ & $62.5(58-73)$ & .4813 & \\
\hline \multicolumn{5}{|l|}{$\mathrm{CT}$} \\
\hline Presence of pannus* & $11(40.74 \%)$ & $18(100 \%)$ & .0002 & .0074 \\
\hline Significant pannus* & $0(0 \%)$ & $10(44.44 \%)$ & .0002 & .0378 \\
\hline Leaflet thickness (mm) & $2.06 \pm 0.78$ & $2.37 \pm 0.96$ & .2353 & .7643 \\
\hline Leaflet thickening $(>2 \mathrm{~mm})^{*}$ & $16(59.26 \%)$ & $15(83.33 \%)$ & .1675 & .1110 \\
\hline MV opening area $\left(\mathrm{cm}^{2}\right)$ & $2.48 \pm 0.73(\mathrm{n}=15)$ & $2.15 \pm 0.69(\mathrm{n}=7)$ & .3219 & .5504 \\
\hline Opening angle of anterior leaflet & $75.32 \pm 14.14(\mathrm{n}=15)$ & $68.47 \pm 6.25(\mathrm{n}=6)$ & .2725 & .2232 \\
\hline Opening angle of posterior leaflet & $80.56 \pm 20.16(n=15)$ & $91.41 \pm 21.22(\mathrm{n}=6)$ & .2855 & .6050 \\
\hline Coaptation angle of anterior leaflet & $26.45 \pm 9.07(\mathrm{n}=11)$ & $22.75 \pm 5.07(\mathrm{n}=6)$ & .3744 & .4980 \\
\hline Coaptation angle of posterior leaflet & $56.26 \pm 20.40(\mathrm{n}=11)$ & $54.45 \pm 10.11(\mathrm{n}=6)$ & .8420 & .7613 \\
\hline Tenting height & $6.23 \pm 1.98(\mathrm{n}=11)$ & $3.94 \pm 1.42(\mathrm{n}=6)$ & .0254 & .1289 \\
\hline Maximal annular diameter (mm) & $28.07 \pm 2.35$ & $26.61 \pm 2.35(\mathrm{n}=16)$ & .0564 & .0880 \\
\hline Minimal annular diameter (mm) & $17.03 \pm 1.23$ & $18.55 \pm 2.14(\mathrm{n}=16)$ & .0170 & .0361 \\
\hline Sphericity index of mitral annulus $\dagger$ & $1.64(1.62-1.70)$ & $1.41(1.32-1.50, \mathrm{n}=16)$ & .0002 & .0015 \\
\hline Annular area measured on CT $\left(\mathrm{cm}^{2}\right)$ & $3.85 \pm 0.54$ & $3.94 \pm 0.54(\mathrm{n}=16)$ & .6012 & .9034 \\
\hline Inserted ring size (manufacturer value, $\mathrm{mm}$ ) & $29.85 \pm 1.89$ & $29.06 \pm 1.11$ & .0890 & \\
\hline
\end{tabular}

Unless otherwise indicated, data are mean \pm SD. $P G$, Pressure gradient; $M V A$, mitral valve area; $C T$, computed tomography; $M S$, mitral stenosis; $M V$, mitral valve. *Data are numbers of patients, with percentages in parentheses. $\dagger$ Data are median and interquartile range (25th-75th percentile).

\section{Comparison of CT Findings Between the Duran Ring and the CE Ring}

On TTE, patients with the Duran ring had a higher mean diastolic PG, a smaller MVA, and a higher incidence of functional MS than patients with the $\mathrm{CE}$ ring $(P<.05$; Table 3). PG was gradually elevated in the Duran ring group as time passed $(0.19 \mathrm{~mm} \mathrm{Hg} / \mathrm{y})$ to a statistically significant extent $(P=.0018)$ but not in the $\mathrm{CE}$ ring group $(P=.1101$; Figure 5). A $P$ value for comparison of the interactions was .0013 , which represented a significant difference between 2 ring types. The proportion of pannus and significant pannus was significantly higher in patients with the Duran ring, even after adjustment for interval $(P<.05)$. Leaflet thickening was not different between the 2 ring types. The mitral opening area on CT was smaller for patients with the Duran ring than for patients with the $\mathrm{CE}$ ring, although no statistical significance was found. The size of the inserted annuloplasty ring and the annular area measured on CT were not different between the 2 types, but patients with the Duran ring showed significantly smaller maximal annular diameter, larger minimal diameter, and smaller annular sphericity index than patients with the $\mathrm{CE}$ ring.

Among the entire study population of 45 patients, 3 patients underwent reoperation, 1 for MS after having the Duran ring inserted and another 2 for detachment of the Duran ring (Figure 6).

\section{DISCUSSION}

Our study demonstrates that patients with functional MS on TTE had more significant pannus formation on CT than did patients with normal range PG. Patients with the Duran ring had a higher incidence of pannus formation around the annuloplasty ring and a smaller opening area on CT. Patients with significant pannus formation on CT tended to have a smaller MVA and a higher mean diastolic PG than did patients with no or insignificant pannus.

Previous studies reported that the Duran ring was associated with a higher incidence of MS and a higher reoperation rate for MS than was the CE ring, despite no significant difference in overall survival or recurrent mitral regurgitation-free survival. ${ }^{6,7}$ The higher incidence of MS in patients with the Duran ring has been thought to be caused by pannus formation. Our study results showed a higher incidence of pannus on CT and an elevated PG on TTE for the Duran ring, and this finding was consistent with results from previous studies.

The reason that pannus around the annuloplasty ring causes MS has not been clearly explained to date. Operative findings in reoperation cases of previous studies, however, have suggested that pannus around the ring causes leaflet thickening and restriction, leading to MS. In previous studies, TTE was used for evaluation before reoperation and could not properly detect pannus formation as 


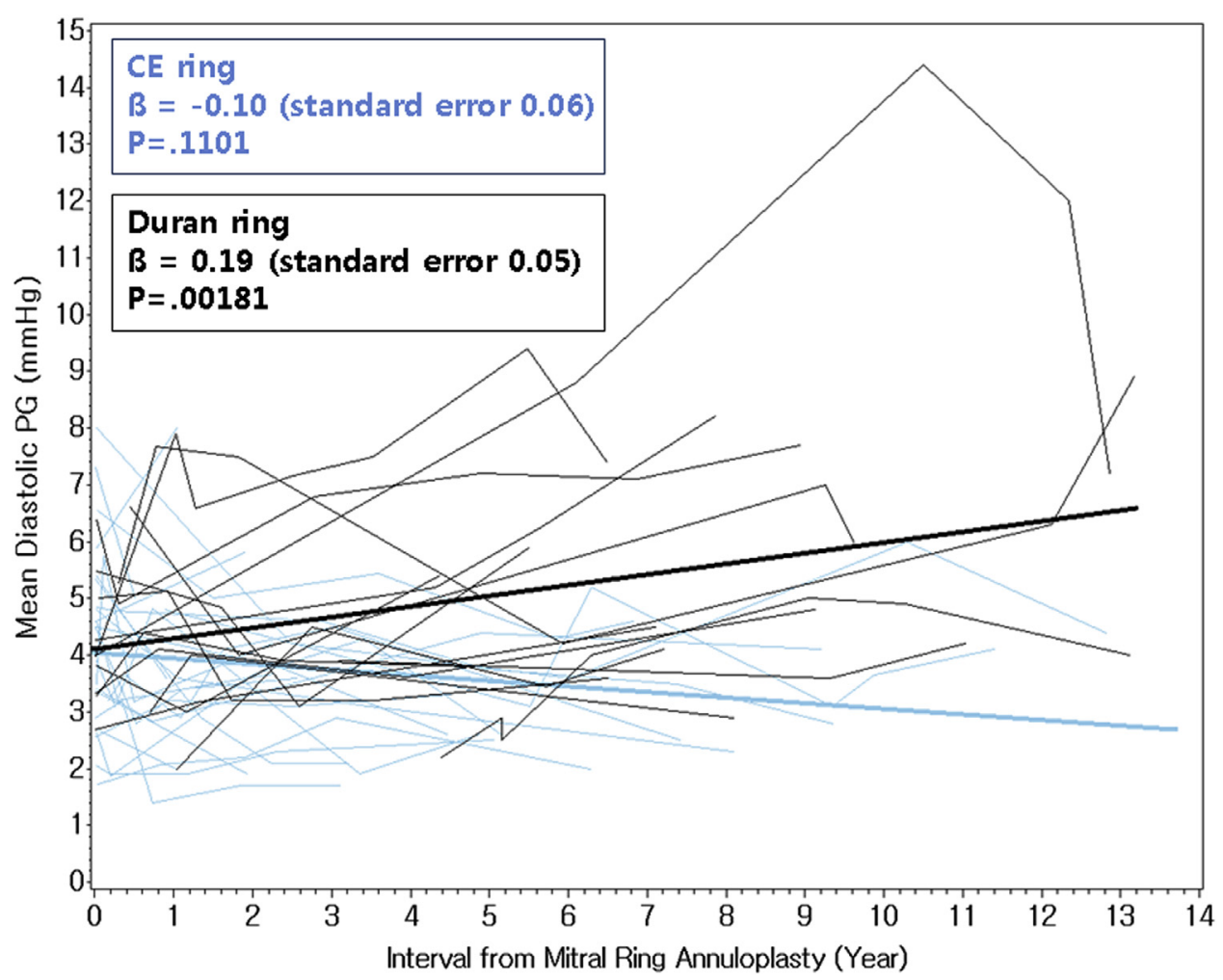

FIGURE 5. Spaghetti plots of mean diastolic pressure gradient $(P G)$ changes according to the interval from mitral ring annuloplasty. Mean diastolic pressure gradient is gradually elevated in the Duran ring as time passes $(0.19 \mathrm{~mm} \mathrm{Hg} / \mathrm{y})$ with statistical significance but not in the Carpentier-Edwards $(C E)$ ring.

the cause of MS before reoperation. ${ }^{6-10}$ In our study, we not only found significant pannus on cardiac CT but also were able to measure the leaflet thickness and valve opening area. The significant pannus formation with leaflet thickening and the decreased mitral opening area on CT that were observed in our study were consistent with the operative findings of previous studies. Notably, although the inserted ring size and the measured annular area on CT were not different between the 2 ring types, the Duran ring had a more circular annular shape than that of the $\mathrm{CE}$ ring.

Ring annuloplasty alters the normal geometry of the MV annulus and restricts posterior leaflet motion of the MV. ${ }^{18,19}$ Changes in MV geometry and leaflet motion after MV annuloplasty have been extensively investigated with TTE and fluoroscopy ${ }^{18,20-24}$ and rarely with CT. ${ }^{14}$ The natural saddle shape of the MV annulus, which changes dynamically throughout the cardiac cycle, is believed to change after ring annuloplasty. Immobilization of the posterior leaflet of the MV leads to the monocusp behavior of the anterior leaflet. ${ }^{18,25}$ Although some of the measured parameters representing mitral geometry, such as the opening and coaptation angles of mitral leaflets, were not different between the 2 ring types, the annular shape on CT seemed to be different. Although the manufacturer ring size was not different between the 2 groups, the Duran ring showed a more circular shape, represented by the smaller maximal diameter and larger minimal diameter of the annulus and the smaller sphericity index (approaching 1.0). The difference in mitral annular shape between the 2 ring types may have resulted from a difference in flexibility. Namely, the rigid CE ring can maintain its shape, whereas the flexible Duran ring changes its shape with annular motion in vivo. ${ }^{26}$ This difference in annular shape may cause more frequent development of pannus formation in the Duran ring. Further study will be needed, however, to investigate the influence of annular shape on pannus formation after MV ring annuloplasty.

Even if TTE can evaluate mean diastolic PG and valve leaflet motion after mitral ring annuloplasty, it has several limitations. The most important limitation is that $P G$ is flow dependent, reflecting cardiac output, and may not accurately reflect the degree of MS. In addition, grading the severity of MS in cases with pannus formation may be challenging, because Doppler parameters are not as reliable and planimetry at the level of the leaflet tips can be misleading because the level of obstruction is mainly at the level of the annuloplasty ring. ${ }^{27}$ Cardiac CT can be helpful in this setting, because it allows direct estimation of the area where stenosis occurs.

Although the Duran ring has been known to have higher PG than the $\mathrm{CE}$ ring after MV repair, the clinical 

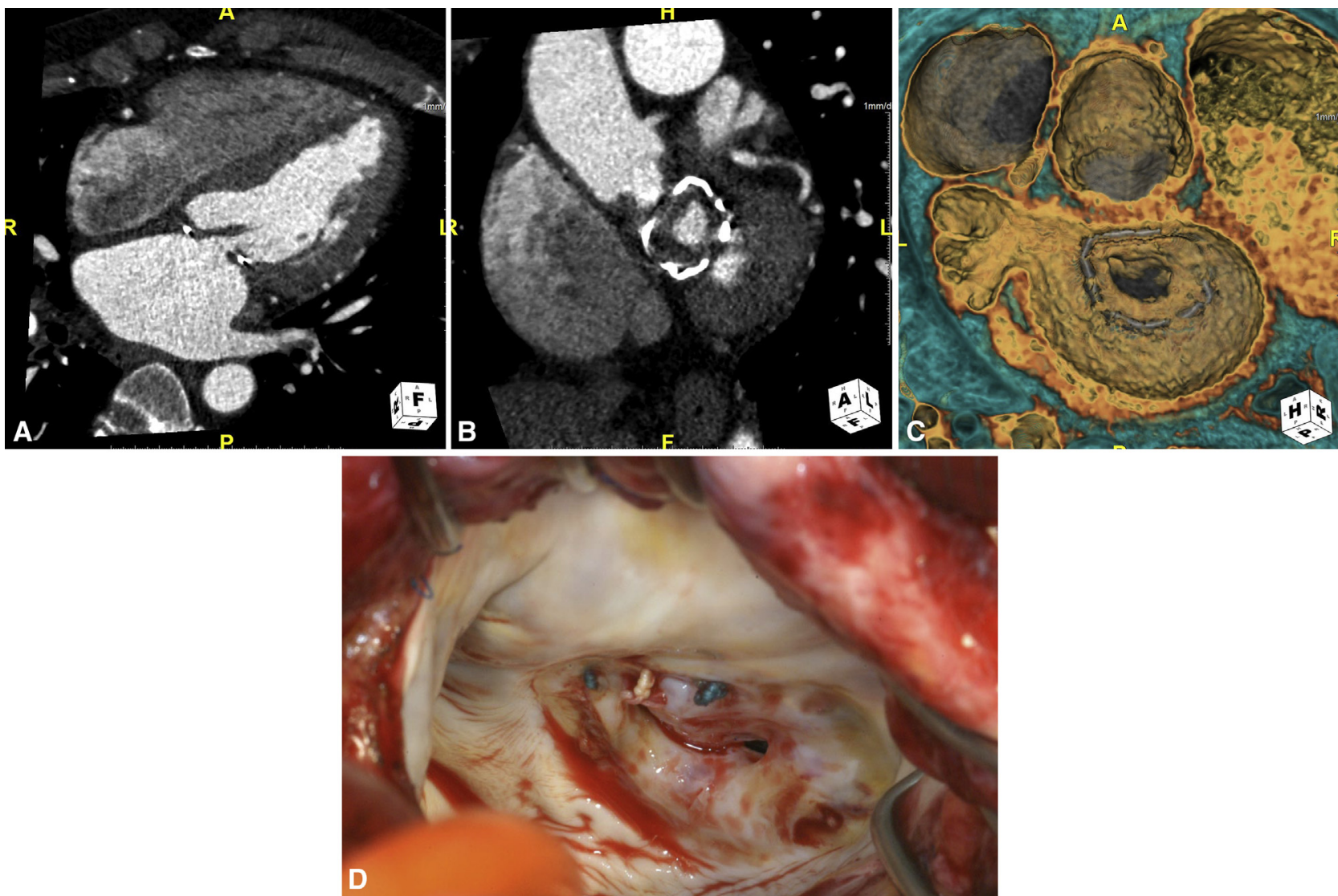

FIGURE 6. Significant pannus formation causing mitral stenosis in a 52-year-old male patient with the Duran annuloplasty ring. A through C, Computed tomographic images of a patient with a 31-mm Duran ring show leaflet thickening of the mitral valve (A) and severe pannus formation around the annular ring (B and C). The patient underwent mitral ring annuloplasty 16 years before computed tomographic scanning because of subacute infective endocarditis. Mean diastolic pressure gradient on transthoracic echocardiography was elevated (18 $\mathrm{mm} \mathrm{Hg}$ ). D, Severe fibrosis of the mitral valve with a circumferential pannus was seen during reoperative surgery.

significance of elevated PG and definition of functional MS after MV repair are still controversial. Many studies have reported that elevated $\mathrm{PG}$ is not uncommon after MV repair. Some investigators have suggested that PG elevation is associated with worse intracardiac hemodynamics and lower exercise capacity. ${ }^{28}$ In comparison, other studies have reported that PG does not correlate with functional capacity ${ }^{29,30}$ and does not reflect the flow dynamic changes after MV repair. ${ }^{29}$ The optimal TTE parameters for the follow-up of patients with MV repairs need to be clarified in the future. Nevertheless, CT can have a complementary role to TTE, because it can demonstrate leaflet morphology, annular geometry, and pannus severity, which can be well correlated with PG on TTE.

Our study has several limitations. First, patient characteristics, such as the cause of underlying MV disease, surgical technique of MV repair, CT indication, and CT acquisition protocol, were relatively heterogeneous because of the retrospective nature of this study. Some patients did not have multiphase CT data, largely because most CT indications were follow-up for coronary artery bypass graft or coronary artery evaluation, and valve motion was not evaluated in these patients. Second, the evaluation for pannus severity may be subjective; to overcome subjectivity, however, we used both qualitative visual grading of pannus severity and a quantitative method. Third, the number of reoperation cases from MS was too small, because we retrospectively enrolled patients who had undergone cardiac CT scan after MV repair. We expect that a future study with a larger population can correlate CT findings with surgical findings and solve this problem. Finally, annuloplasty with a complete ring may be associated with higher MV gradients at rest and at peak exercise than annuloplasty with a posterior band, ${ }^{3}$ and posterior annuloplasty band are being used increasingly. We did not encounter follow-up CT imaging of patients with the posterior annuloplasty band, however, because the procedure has only been performed since 2006 in our institution. We suggest that careful inspection of CT findings with respect to the presence of pannus formation in patients with the posterior annuloplasty band is needed in the future. 
In conclusion, significant pannus around the annuloplasty ring on CT may cause functional MS after mitral ring annuloplasty, and this may occur more frequently for the Duran ring. Cardiac CT can be helpful in patients with Duran ring annuloplasty who show elevated PG by further evaluating the cause of their PG elevation.

\section{Conflict of Interest Statement}

Authors have nothing to disclose with regard to commercial support.

We thank Kyunghwa Han, PhD, Biostatistics Collaboration Unit, Yonsei University College of Medicine, for her statistical consultation.

\section{References}

1. Gelsomino S, van Garsse L, Luca F, Lorusso R, Cheriex E, Rao CM, et al. Impact of preoperative anterior leaflet tethering on the recurrence of ischemic mitral regurgitation and the lack of left ventricular reverse remodeling after restrictive annuloplasty. J Am Soc Echocardiogr. 2011;24:1365-75.

2. Jyrala A, Gatto NM, Kay GL. Measured posterior annuloplasty for repair of nonischemic mitral regurgitation. A single unit follow-up. Interact Cardiovasc Thorac Surg. 2010;10:81-5.

3. Mesana TG, Lam BK, Chan V, Chen K, Ruel M, Chan K. Clinical evaluation of functional mitral stenosis after mitral valve repair for degenerative disease: potential affect on surgical strategy. J Thorac Cardiovasc Surg. 2013;146: 1418-23; discussion 1423-5.

4. Ghersin N, Abadi S, Sabbag A, Lamash Y, Anderson RH, Wolfson H, et al. The three-dimensional geometric relationship between the mitral valvar annulus and the coronary arteries as seen from the perspective of the cardiac surgeon using cardiac computed tomography. Eur J Cardiothorac Surg. 2013;44:1123-30.

5. Fino C, Iacovoni A, Ferrero P, Senni M, Merlo M, Cugola D, et al. Restrictive mitral valve annuloplasty versus mitral valve replacement for functional ischemic mitral regurgitation: an exercise echocardiographic study. J Thorac Cardiovasc Surg. 2014;148:447-53.e2.

6. Ibrahim MF, David TE. Mitral stenosis after mitral valve repair for nonrheumatic mitral regurgitation. Ann Thorac Surg. 2002;73:34-6.

7. Chung CH, Kim JB, Choo SJ, Kim KS, Song H, Song MG, et al. Long-term outcomes after mitral ring annuloplasty for degenerative mitral regurgitation: Duran ring versus Carpentier-Edwards ring. J Heart Valve Dis. 2007; 16:536-44; discussion 544-5.

8. Song S, Cho SH, Yang JH, Park PW. Repair for mitral stenosis due to pannus formation after Duran ring annuloplasty. Ann Thorac Surg. 2010;90:e93-4.

9. Nishida H, Takahara Y, Takeuchi S, Mogi K. Mitral stenosis after mitral valve repair using the Duran flexible annuloplasty ring for degenerative mitral regurgitation. J Heart Valve Dis. 2005;14:563-4.

10. Yunoki J, Minato N, Katayama Y, Sato H. Mitral valve stenosis caused by abnormal pannus extension over the prosthetic ring and leaflets after Duran ring mitral annuloplasty. J Card Surg. 2009;24:143-5.

11. Chang BC, Youn YN, Ha JW, Lim SH, Hong YS, Chung N. Long-term clinical results of mitral valvuloplasty using flexible and rigid rings: a prospective and randomized study. J Thorac Cardiovasc Surg. 2007;133:995-1003.

12. Feuchtner GM, Alkadhi H, Karlo C, Sarwar A, Meier A, Dichtl W, et al. Cardiac CT angiography for the diagnosis of mitral valve prolapse: comparison with echocardiography. Radiology. 2010;254:374-83.

13. Lembcke A, Durmus T, Westermann Y, Geigenmueller A, Claus B, Butler C, et al. Assessment of mitral valve stenosis by helical MDCT: comparison with transthoracic Doppler echocardiography and cardiac catheterization. AJR Am J Roentgenol. 2011;197:614-22.

14. Shudo Y, Matsumiya G, Sakaguchi T, Miyagawa S, Yoshikawa Y, Yamauchi T, et al. Assessment of changes in mitral valve configuration with multidetector computed tomography: impact of papillary muscle imbrication and ring annuloplasty. Circulation. 2010;122(11 Suppl):S29-36.

15. Delgado V, Tops LF, Schuijf JD, de Roos A, Brugada J, Schalij MJ, et al. Assessment of mitral valve anatomy and geometry with multislice computed tomography. JACC Cardiovasc Imaging. 2009;2:556-65.

16. Mihalatos DG, Joseph S, Gopal A, Bercow N, Toole R, Passick M, et al. Mitral annular remodeling with varying degrees and mechanisms of chronic mitral regurgitation. J Am Soc Echocardiogr. 2007;20:397-404.

17. Hamlett A, Ryan L, Serrano-Trespalacios P, Wolfinger R. Mixed models for assessing correlation in the presence of replication. J Air Waste Manag Assoc. 2003;53:442-50.

18. Green GR, Dagum P, Glasson JR, Nistal JF, Daughters GT II, Ingels NB Jr, et al. Restricted posterior leaflet motion after mitral ring annuloplasty. Ann Thorac Surg. 1999;68:2100-6.

19. Glasson JR, Green GR, Nistal JF, Dagum P, Komeda M, Daughters GT, et al. Mitral annular size and shape in sheep with annuloplasty rings. J Thorac Cardiovasc Surg. 1999;117:302-9.

20. Dagum P, Timek T, Green GR, Daughters GT, Liang D, Ingels NB Jr, et al. Threedimensional geometric comparison of partial and complete flexible mitral annuloplasty rings. J Thorac Cardiovasc Surg. 2001;122:665-73.

21. Ryan LP, Jackson BM, Hamamoto H, Eperjesi TJ, Plappert TJ, St John-Sutton M, et al. The influence of annuloplasty ring geometry on mitral leaflet curvature. Ann Thorac Surg. 2008;86:749-59; discussion 759-60.

22. Mahmood F, Gorman JH III, Subramaniam B, Gorman RC, Panzica PJ, Hagberg RC, et al. Changes in mitral valve annular geometry after repair: saddle-shaped versus flat annuloplasty rings. Ann Thorac Surg. 2010;90: 1212-20.

23. Jensen MO, Jensen H, Smerup M, Levine RA, Yoganathan AP, Nygaard H, et al. Saddle-shaped mitral valve annuloplasty rings experience lower forces compared with flat rings. Circulation. 2008;118(14 Suppl):S250-5.

24. Jensen MO, Jensen H, Levine RA, Yoganathan AP, Andersen NT, Nygaard H, et al. Saddle-shaped mitral valve annuloplasty rings improve leaflet coaptation geometry. J Thorac Cardiovasc Surg. 2011;142:697-703.

25. Kuwahara E, Otsuji Y, Iguro Y, Ueno T, Zhu F, Mizukami N, et al. Mechanism of recurrent/persistent ischemic/functional mitral regurgitation in the chronic phase after surgical annuloplasty: importance of augmented posterior leaflet tethering. Circulation. 2006;114(1 Suppl):I529-34.

26. Okada Y, Nasu M, Kanzaki J. Flexibility of the mitral annulus with the Duran ring at six years post-implantation. J Heart Valve Dis. 2002;11:32-8.

27. Sachpekidis V, Agatziotis M, Styliadis I, Mosialos L, Kaprinis I, Monaghan MJ, et al. Three-dimensional imaging of pannus overgrowth after mitral valve repair. Echocardiography. 2012;29:E210-3.

28. Chan KL, Chen SY, Chan V, Hay K, Mesana T, Lam BK. Functional significance of elevated mitral gradients after repair for degenerative mitral regurgitation. Circ Cardiovasc Imaging. 2013;6:1041-7.

29. Bertrand PB, Gutermann H, Smeets CJ, Van Kerrebroeck C, Verhaert D, Vandervoort $\mathrm{P}$, et al. Functional impact of transmitral gradients at rest and during exercise after restrictive annuloplasty for ischemic mitral regurgitation. J Thorac Cardiovasc Surg. 2014;148:183-7.

30. Williams ML, Daneshmand MA, Jollis JG, Horton JR, Shaw LK, Swaminathan M, et al. Mitral gradients and frequency of recurrence of mitral regurgitation after ring annuloplasty for ischemic mitral regurgitation. Ann Thorac Surg. 2009;88:1197-201.

Key Words: mitral valve repair, ring annuloplasty, functional mitral stenosis, pannus, computed tomography 